\title{
De Novo Creari: \\ Análise de manuscritos escolares por meio de tópicos de intertextualidade e criatividade ${ }^{1}$
}

\author{
De Novo Creari: \\ School manuscript analysis through intertextuality and \\ creativity topics
}

\section{De Novo Creari: \\ Analysis de manuscritos escolares por medio de tópicos de intertextualidad y creatividad}

\author{
Bruno Jaborandy Maia Dias² \\ Adna Almeida Lopes ${ }^{3}$ \\ Eduardo Calil ${ }^{4}$
}

RESUMO: Desde sua teorização inicial (TATARKIEWICK, 1980; KOLP, 2009) a criatividade vem sendo estudada por meio de diversas abordagens, a que trata da produção textual em sala de aula (ALBUQUERQUE, 1992; MAKSIĆ; ŚEVKUŠIĆ, 2012; GRAINGER, GOOUCH; LAMBIRTH, 2005) nos aponta que temos na intertextualidade (KRISTEVA; 1986; BEAUGRANDE; DRESSLER, 1981; BAZERMAN, 2007, 2011; KOCH et al., 2008, 2010) um forte

\footnotetext{
${ }^{1}$ Este estudo recebeu o apoio do CNPq (processo 304050/2015-6) e bolsa de Mestrado da Fundação de Amparo à Pesquisa do Estado de Alagoas, em convênio com a Capes (processo 20121031002-0032 -0031).

2 Doutorando em Linguística do Programa de Letras e Linguística da Universidade Federal de Alagoas. Mestre em Educação pela Universidade Federal de Alagoas. Graduado em Comunicação Social com Habilitação em Jornalismo pela Universidade Federal de Alagoas.

3 Possui graduação em Letras pela Universidade Federal de Alagoas (1991), mestrado em Letras e Linguística pela Universidade Federal de Alagoas (1996) e doutorado em Letras e Linguística pela Universidade Federal de Alagoas (2005). Atualmente é Professor Associado da Universidade Federal de Alagoas. Tem experiência na área de Linguística, com ênfase em Psicolinguística, atuando principalmente nos seguintes temas: ensino, leitura e escrita, escrita, erro e alfabetização.

${ }^{4}$ Professor-associado da Universidade Federal de Alagoas (UFAL), coordenador do Laboratório do Manuscrito Escolar (LAME), pesquisador associado ao CNPq e ao Instituto de Textos e Manuscritos Modernos (ITEM/Paris). Autor de livros e artigos sobre manuscritos escolares e processos de escritura, nos quais destaca a importância da criação textual e da rasura oral no trabalho colaborativo entre alunos recém-alfabetizados. Atualmente é responsável pelo desenvolvimento do projeto InterWriting, que envolve pesquisadores brasileiros, franceses, portugueses e espanhóis.
} 
indício de que um texto é mais criativo, junto a critérios específicos de criatividade a serem analisados e aspectos próprios da escritura no contexto de sala de aula (CALIL, 2007, 2008, 2009, 2010, 2012). Este artigo propõe uma análise de manuscritos produzidos por crianças, recém-saídas do letramento, no ambiente da sala de aula com foco principal em determinar de que maneira um texto pode ser considerado criativo, para isso, definimos quatro tópicos, que se subdividem em dezenove critérios. Dois tópicos são relativos a intertextualidade (ampla e pela padronização da linguagem social em uso) e dois são relativos a criatividade (brincadeira com a linguagem e originalidade de ideias, autenticidade e imaginatividade). Nosso corpus é composto por 143 manuscritos, resultado do projeto 'Contos do Como e do Por que' realizado em escola particular de Maceió, Alagoas, Brasil. Desse total de manuscritos escolhemos 20 deles para uma análise mais aprofundada e os resultados apontaram a proporção de $65 \%$ de critérios de intertextualidade contra $35 \%$ de criatividade. Apresentamos também a análise textualizada de dois desses manuscritos. Os dados e resultados obtidos apontam para uma proposta inicial de definição de criatividade na produção de textos em contexto escolar.

PALAVRAS-CHAVE: Criatividade. Intertextualidade. Análise Textual.

ABSTRACT: Since its initial theorization, (TATARKIEWICK, 1980; KOLP, 2009) creativity is studied through multiple approaches. The classroom textual production approach (ALBUQUERQUE, 1992; MAKSIĆ; ŠEVKUŠIĆ, 2012; GRAINGER, GOOUCH; LAMBIRTH, 2005) points out that we have in intertextuality (KRISTEVA, 1986; BEAUGRANDE; DRESSLER, 1981; BAZERMAN, 2007, 2011; KOCH et al., 2008, 2010) a strong token that a text is more creative, allied to criteria specific to creativity to be analyzed and proper aspects of the classroom writing (CALIL, 2007, 2008, 2009, 2012). This paper proposes an analysis of school manuscripts, produced by recently-literate children, in the classroom environment with the main goal of determining in which way a text can be considered creative, this way we defined four topics, that are subdivided in nineteen criteria. Two topics are related to intertextuality (wide and by the standardization of the social language at use) and two are related to creativity itself (playing with language and idea originality, authenticity and imagination). Our corpus is composed of 143 manuscripts, result of the 'Tales of How and Why' project, made in a private school in Maceió, Alagoas, Brazil. From these manuscripts, we chose 20 to a deeper analysis and the results pointed out the proportion of $65 \%$ intertextuality criteria over $35 \%$ of creativity criteria. We also present the textual analysis of two of these manuscripts. The data and results obtained offer us an initial definition of creativity of text production in the school context.

KEYWORDS: Creativity. Intertextuality. Textual Analysis.

RESUMEN: Hace su teorización inicial (TATARKIEWICK, 1980; KOLP, 2009) la creatividad ha sido estudiada por medio de múltiples enfoques, lo que trata de la producción textual en clase (ALBUQUERQUE, 1992; MAKSIĆ; ŠEVKUŠIĆ, 2012; GRAINGER, GOOUCH; LAMBIRTH, 2005) nos apunta que tenemos en la intertextualidad (KRISTEVA, 1984; BEAUGRANDE; DRESSLER, 1981; BAZERMAN, 2007, 2011; KOCH et al., 2008, 2010) un fuerte indicio de que un texto es más creativo, junto a criterios específicos de creatividad a ser analizados y aspectos propios de la escritura en el contexto de la aula (CALIL, 2007, 2008, 2009, 2010, 2012). Ese artículo propone un análisis de los manuscritos producidos por niños, recién-salidos de la alfabetización, en el ambiente de aula con foco principal en determinar de qué manera un texto puede ser considerado creativo, para eso, definimos cuatro tópicos, que se subdividen en diecinueve criterios. Dos tópicos son relativos a la intertextualidad (amplia e por la estandarización del lenguaje social en uso) y dos relativos a la creatividad (juego con el lenguaje y originalidad de ideas, autenticidad e imaginación). Nuestro corpus es compuesto por 143 manuscritos, resultado del proyecto 'Cuentos de lo Como y de lo Por que' realizado en una escuela privativa de Maceió, Alagoas, Brasil. De ese montante, elegimos 20 para un 
análisis más profundo y los resultados nos apuntan la proporción del $65 \%$ de criterios de intertextualidad en contra el $35 \%$ de creatividad. Presentamos también un análisis textualizado de dos de estos manuscritos. Los datos y resultados apuntan una propuesta inicial de definición de creatividad en la producción de textos en contexto escolar.

PALABRAS CLAVES: Creatividad. Intertextualidad. Analysis textual.

\section{Introdução}

A criatividade é tópico de discussão em diversos domínios de expressão: artístico, publicitário, da resolução de problemas na área de negócios ou das ciências exatas. Nosso foco, neste trabalho, é entender de que maneira pode-se afirmar que um texto narrativo (uma história inventada), escrito por crianças recém-alfabetizadas, no ambiente da sala de aula, com uma consigna fornecida pela professora, pode ser tido como mais criativo do que outros textos produzidos sob as mesmas condições.

Para a análise pretendida neste artigo partimos de um encaminhamento teórico dos estudos sobre a criatividade em sua teorização inicial (KOLP, 2009; TATARKIEWICZ, 1980), e sobre a criatividade na produção textual em sala de aula (ALBUQUERQUE, 1992; MAKSIĆ; ŠEVKUŠIĆ, 2012 e GRAINGER; GOOUCH; LAMBIRTH, 2005), nós encontramos na intertextualidade (KRISTEVA, 1970; BEAUGRANDE; DRESSLER, 1981; ANTUNES, 2010; BAZERMAN, 2007, 2011) um possível índice para estabelecimento de uma análise que, junto ao olhar sobre os aspectos próprios da escrita de alunos nos estudos de Calil ${ }^{5}(2004,2007,2008,2009,2012)$ nos permita afirmar porque um texto é criativo e, além disso, apontar uma possível definição do que seja criatividade dentro das condições analisadas.

Para nossa análise de textos foram estabelecidos dois macrocritérios relativos à intertextualidade, que são a intertextualidade ampla e intertextualidade pela padronização da linguagem social em uso. Para uma ampliação dos critérios

\footnotetext{
${ }^{5}$ Em suas pesquisas, Calil desenvolve uma metodologia especificamente voltada para a análise desse tipo de manuscrito, além do entendimento do processo da escrita por meio da gravação em áudio e vídeo dos alunos produzindo textos. Ele define manuscrito escolar como sendo: [...] todo e qualquer escrito mobilizado por uma demanda escolar, seja ele produzido à mão, à máquina ou no computador, seja ele escrito em folha avulsa, no livro didático, no caderno escolar de estudo de Língua Portuguesa, de Matemática, de Ciências, de Geografia, ou ainda uma breve nota, um bilhete, uma história inventada, um conto de fada reescrito, um poema copiado, as respostas a uma prova bimestral de Matemática, a uma questão de Ciências... (CALIL, 2008, p.24).
} 
estabelecidos na análise nós somamos dois macrocritérios a partir do trabalho de Maksic e Ševkušić (2012): brincadeira com a linguagem e originalidade de ideias, autenticidade e imaginatividade. Com os tópicos de análise delineados nós apresentaremos um demonstrativo da frequência do surgimento dos critérios nos manuscritos analisados e, em seguida, uma análise mais detalhada de dois manuscritos 'Como surgiram as palavras' e 'O fogo do vulcão".

\section{A criatividade na produção de textos}

O termo criação surgiu em 1623 e é utilizado pela primeira vez (KOLP, 2009, p.1), pelo polonês Mathias Casimiro Sarbievius em sua obra de análise da poesia épica: De perfecta poesi sive Vergilius et Homerus. Nesse tratado, Sarbievius busca a diferenciação entre "criação" (ato divino ou ato de representação do mundo criado por Deus) e "ato" ou "segunda criação" (TATARKIEWICZ, 1980, p. 248), próprios ao homem. A criação seria o reflexo da qualidade do artista e, portanto, da sua obra de arte. Ele afirmava que um poeta cria o novo (de novo creari)à maneira de Deus (instar del).

A criação continuou a ser abordada de maneira crítica pelos teóricos porém ainda não se falava, explicitamente, em criatividade. Apenas no fim do século XIX, com a intenção de sair do campo clássico de investigação, matemáticos e físicos "estudaram a pertinência da intuição em suas pesquisas abstratas e defenderam um passo criativo" ${ }^{6 \prime}$ (KOLP, 2009, p.1).

Um primeiro estudo que vai em busca de respostas quanto aos textos considerados "criativos" no contexto de sala de aula é o de Albuquerque (1992), realizado com 66 estudantes entre 11 e 12 anos de idade, alunos das escolas da região de Aveiro, em Portugal.

\footnotetext{
${ }^{6}$ A trajetória do termo criatividade, visto pela ciência, passa por Ribot (1906), Jung (1933), J.P. Guilford (1950), Rogers (1961), Torrance (1966), Koestler (1967) e Maslow (1973). No fim do século XX, e do início do século XXI em diante, podemos destacar os trabalhos de Gardner (1993, 1996, 2003, 2013), Csikszentmihalyi (1996) e Robinson (1999, 2012).
} 
A autora fundamenta 0 trabalho na noção de texto $^{7}$ e todos os textos desenvolvidos com os alunos "partem da constatação de que, com maior ou menor precisão, eles sabem o que é um texto; isto é, [...] que todos os alunos parecem ter consciência de que um texto é linguagem". Na concepção da autora, pelos títulos que os alunos dão, tais como "história", "composição", "redação", eles têm consciência de que "o texto é um bloco lingüístico necessariamente coeso e coerente" (ALBUQUERQUE, 1992, p.33).

Após citar as sete condições de textualidade ${ }^{8}$, segundo Beaugrande \& Dressler (1981), a autora faz uma afirmação que consolida a nossa intenção de estreitar o conceito de criatividade seguindo uma dessas sete condições: a intertextualidade. De acordo com a concepção de Albuquerque (1992, p.37), essa é uma das condições de dependência de um texto com relação a outros textos:

\begin{abstract}
Intertextualidade é uma noção particularmente importante para o estudo de texto literário ou outros tipos de textos que apresentem características gerais passíveis de padronização. No caso do texto escolar em estudo, achamos que esta sétima condição de textualidade é também fundamental especialmente tendo em conta que podemos falar dum modelo de texto pedagógico em que os alunos se devem enquadrar e que apenas podem enriquecer com sua experiência pessoal (ALBUQUERQUE, 1992, p. 37, 38).
\end{abstract}

Para a definição de critérios no texto dos alunos procuramos, após uma análise inicial do corpus, decidimos tomar como hipótese essa noção apresentada pela autora de que a intertextualidade é um dos principais indícios de que um texto é criativo.

Indicadores de criatividade na avaliação de histórias dos alunos constam do trabalho de Maksić e Ševkušić ${ }^{9}$ que tem como objetivo avaliar os produtos de crianças criativas no domínio verbal e parte da premissa de que as atividades na escola podem servir de estímulo para a expressão e o desenvolvimento da criatividade dos estudantes. O principal foco é entender "de que maneira a avaliação, pelos professores, da escrita criativa de alunos é confiável e útil para ganhar entendimento

\footnotetext{
7 Para a autora um texto é (ALBUQUERQUE, 1992, p.34) "antes de tudo, um produto da linguagem e linguagem entendida num enquadramento social"

8 "As sete condições de textualidade são: coesão, coerência, intencionalidade, aceitabilidade, informatividade, situacionalidade e intertextualidade" (BEAUGRANDE; DRESSLER apud ALBUQUERQUE, 1992, p.34).

${ }^{9}$ Publicado em 2012.
}

Entretextos, Londrina, v. 17, n. 2, p. 77 - 103, jul./ dez. 2017 
da produção criativa de estudantes nesse domínio" (MAKSIĆ; ŠEVKUŠIĆ, 2012, p. 129).

Os principais questionamentos do trabalho versam sobre a maneira como os professores concordam na avaliação da criatividade dos estudantes nas histórias escritas, sobre quais crenças implícitas (dos professores) manifestam-se na avaliação da criatividade e de que maneira são descritos os estudantes tidos como mais criativos, de acordo com indicadores relevantes de suas habilidades e de seu potencial criativo.

A pesquisa foi conduzida com 152 participantes, das $6^{a}$ e $7^{a}$ série do sistema educacional sérvio, com idades entre 13 e 14 anos, de uma mesma escola no centro de Belgrado. Os produtos finais, no entanto, contaram com os trabalhos de 142 estudantes, que atingiram as três variáveis iniciais do estudo, 80 estudantes da sexta série e 62 da sétima, 63 garotos e 79 garotas.

Três professoras da escola primária sérvia, das disciplinas de língua sérvia e literatura, participaram do estudo. As variáveis e os instrumentos do estudo desenvolvido pelas autoras, foram:

a) Produção escrita no domínio verbal: a escrita de histórias;

b) Fluência verbal;

c) Interesses: divididos em interesse gerale interesse em ciências sociais e linguagem;

d) Realização acadêmica geral;

e) Realização acadêmica em língua sérvia;

f) Conhecimento da ortografia e da gramática sérvia.

(MAKSIĆ; ŠEVKUŠIĆ, 2012, p. 130).

O procedimento do estudo consistia em que os alunos fizessem um desenho e depois escrevessem uma história. A possibilidade de escolher um título foi deixada a contento. Quase todos os participantes escreveram sobre o que tinham desenhado. Desses, apenas um terço deu um título à história. Os textos foram digitados, de maneira a evitar os efeitos da escrita manual e dos erros de ortografia na criatividade estimada (MAKSIĆ; ŠEVKUŠIĆ, 2012, p. 132). As informações sobre os autores eram apenas duas: série e gênero. As professoras deram, então, notas às histórias em uma escala de 1 a 5 , sendo 1 não criativa e 5 a mais criativa, utilizando-se uma abordagem global-integradora baseada na primeira impressão. 
Os critérios de valorização da originalidade, autenticidade, individualidade, qualidade emocional e dimensão ética foram uma unanimidade entre as professoras. Os autores da pesquisa afirmam que descobertas confirmam a teoria de que o conceito de "trabalho criativo" no Ocidente dá ênfase aos elementos pessoais, intrapsíquicos e emocionais. As três professoras afirmaram que a idade das crianças poderia comprometer seu potencial criativo, mas valorizaram a expressão espontânea. Para elas, alguns dos adjetivos mais importantes na descrição da criatividade foram "afetiva, artística, emocional, humorística, imaginativa, inventiva, original, espontânea" (MAKSIĆ; ŠEVKUŠIĆ, 2012, p. 135). De maneira geral, os ensaios forneceram importantes informações para a maneira pela qual as professoras julgavam a criatividade, mas essas informações não puderam ser diretamente aplicadas na prática escolar. ${ }^{10}$

Uma análise narrativa ${ }^{11}$ das quatro histórias selecionadas permitiu às pesquisadoras observarem que três delas estavam no formato de ensaio e uma era um poema. Os três ensaios foram nomeados; já o poema convidava o leitor a vir com sua própria denominação. Os títulos já davam uma ideia do aspecto não convencional dos textos e possuíam elementos de ficção e de contradição, tais como Anarquia infinita, Insanidade mútua e Desfrutando a não-liberdade.

As pesquisadoras concluem, então, que a avaliação pelas professoras das histórias dos alunos pode ser utilizada como uma maneira útil e econômica de nutrir o potencial criativo dos estudantes no domínio da escrita. A análise quantitativa dos dados sugere que ${ }^{12}$

\footnotetext{
${ }^{10}$ Os quatro estudantes que produziram as histórias consideradas mais criativas eram garotas, duas delas da sexta série e duas, da sétima. A estudante de número quatro pertencia ao top $25 \%$ da classe em termos de fluência, escopo de interesses e intensidade do seu interesse nas ciências sociais e nas línguas. As diferenças nos perfis dessas "top 4" criativas não permitiu às autoras construir um perfil consistente do jovem criativo escritor de histórias, algo que pudesse ser preciso o suficiente para permitir sua identificação, com o propósito de oferecer uma estrutura adequada no contexto escolar. Não foi possível, desse modo, desenhar um perfil típico com contribuição crítica para qualquer indicador ou precondição para a produção criativa.
}

${ }^{11} \mathrm{O}$ aporte teórico utilizado pelas autoras é composto pelo teste de medidas de criatividade de Sternberg (2006), conhecido como STAT, além da Avaliação de Criatividade Potencial (LUBART, 2008).

12 No original: "an individual approach in interpreting data on the child's talents at the primary school level is necessary. At this level, all the indicators, which point to exceptional performance in the relevant 


\begin{abstract}
Uma abordagem individual na interpretação de dados sobre os talentos na escola primária é necessária. Nesse nível, todos os indicadores que apontam para a performance excepcional nos aspectos relevantes são importantes. No entanto, os baixos resultados não significam que uma criança não tem talento para a escrita. A abordagem qualitativa na avaliação [...]contribui para uma descrição mais completa do produto criativo do que a quantitativa, já que mostra a diversidade e riqueza de componentes e resultados embutidos no produto criativo (MAKSIĆ; ŠEVKUŠIĆ, 2012, p. 140).
\end{abstract}

Entendendo que a escola reforça a noção linear da escrita criativa, os autores apontam que seria importante também considerar a abordagem qualitativa na avaliação do produto textual e tornar os alunos e alunas familiares com os aspectos de textos não-lineares. $O$ trabalho das pesquisadoras sérvias mostra-se essencial para nós ao indicar principalmente os tópicos de análise da criatividade em textos de alunos da escola primária.

Tomando a criatividade na escrita de crianças sob o ponto de vista pedagógico, ou seja, observado pelos professores de língua e escrita, a obra de Grainger, Goouch e Lambirth (2005) oferece importantes pistas sobre como essa questão pode ser trabalhada nas escolas. Para os autores, é evidente a necessidade de um equilíbrio entre conhecimento sobre a língua e o uso da linguagem criativa.

Na obra, é ressaltada a complexidade do ensino da escrita, que permite tanto o aprendizado por meio da atividade imaginativa, quanto como no apoio em exemplos. Para os autores, se a escrita das crianças funciona como um possível indicador da criatividade, a raiz de suas histórias precisa ser sempre nutrida. Realizado durante dois anos, de 2001 a 2003, o projeto We'reWriters (Somos Escritores), teve como objetivo observar como "explorar como as vozes escritas das crianças poderiam ser melhoradas por meio do empoderamento de professores para usar e explorar seu potencial próprio, assim como o das crianças" (GRAINGER; GOOUCH; LAMBIRTH, 2005, p.2).

Um dos principais pontos fortalecidos na pesquisa foi o de que as crianças constroem seus entendimentos das oportunidades, experiências e prioridades criadas em suas escolas. Na opinião dos autores, tal afirmação deve servir de advertência aos

aspects, are important. However, lower achievement does not mean that a child does not have a talent for writing. Qualitative approach in assessment of the written stories contributes to a more thorough description of the creative product than the quantitative measure, since it shows the diversity and richness of components and meanings embedded in the creative product". 
envolvidos com o ensino da escrita, ou seja, crianças escrevem de forma mais contundente "quando estão totalmente envolvidas na experiência da composição e não estão fora do enquadramento, manuseando as ferramentas da comunicação escrita em maneira distante ou aparentemente acadêmica"13 (GRAINGER; GOOUCH; LAMBIRTH, 2005, p.8).

Seria necessário, então, retomar a brincadeira, pela qual a criatividade aflora. Para os autores, esse tipo de atividade é geralmente sério, inspirado e exigente e nasce das interações com outros, com as ideias e com a experiência: "o processo criativo da escrita envolve-nos em fazer escolhas sobre nossa postura, conteúdo, estrutura e linguagem e criar combinações e conexões entre ideias e imagens"14 (GRAINGER; GOOUCH; LAMBIRTH, 2005, p.13).

Um ponto no trabalho dos autores que podemos tomar como uma intersecção com o nosso trabalho é a questão da intertextualidade, múltipla e difusa, nos produtos criativos das crianças:

O que as crianças querem falar e escrever sobre, é influenciado pelos textos que elas ouviram, viram, leram, assistiram e brincaram com: os livros, histórias, rimas, canções, televisão, filmes, peças de teatro, videogames e artefatos que constroem seu diálogo com a cultura. As crianças se apropriam de vozes desses vários textos na sua escrita, transformando e remodelando suas próprias vozes nesse processo (GRAINGER; GOOUCH; LAMBIRTH, 2005, p.30). ${ }^{15}$

Apontamos para essa direção quando optamos por observar a criatividade nos textos sobre o viés da intertextualidade, nesse intenso diálogo entre o que as crianças absorvem e o quanto disso elas conseguem retrabalhar, para trazer à tona textos que contribuam significativamente no avanço do domínio simbólico da escrita. Para os autores do texto, a intertextualidade "pode engendrar originalidade, quando as

\footnotetext{
${ }^{13}$ No original: "when they are fully involved in the compositional experience and are not outside the frame, handling the tools of written communication in a distant or apparently academic manner".

${ }^{14}$ No original: "The creative process of writing involves us in making choices about our stance, content, structure and language, and creating combinations and connections between ideas and images".

${ }^{15}$ No original: "What children want to talk and write abou tis influenced by the texts that they have heard, seen, read, watched and played with: the books, stories, rhymes, songs, television, film, dramas, video games and artefacts that make up their dialogue with their culture. Children appropriate voices from these various texts in their writing, transforming and re-shaping their own voices in the process".
} 
conexões se originam da persona do criador" ${ }^{16}$ (GRAINGER; GOOUCH; LAMBIRTH, 2005, p.36, 37). Tal afirmação parte da premissa de que a criatividade se apoia em formas socialmente estabelecidas, mas incorpora o original para, assim, gerar alternativas e extensões, que são, por sua vez, influenciadas pela grande variedade de vozes com as quais as crianças estão familiarizadas. Elas se apropriam dessas formas, exploram e adaptam ao tamanho das suas habilidades no domínio da escrita.

Por meio desse encaminhamento teórico pudemos perceber a estreita ligação entre intertextualidade e criatividade, quando tratamos de textos escritos por crianças. No próximo tópico dissertaremos sobre a intertextualidade em si e os caminhos pelos quais a utilizamos na criação de nossa análise própria.

\section{Intertextualidade: consolidação do termo e critérios de textualidade}

Atentar-nos-emos a definir de que maneira um texto pode ser considerado criativo tendo a intertextualidade como indício. Para um aprofundamento das questões relativas à intertextualidade, tentamos uma delimitação do conceito - nascimento, evolução e aperfeiçoamento - sua relação com o dialogismo, a produção de sentidos e a análise textual.

Costa Val explica que os estudiosos da Linguística Textual veem o texto como uma "unidade linguística comunicativa básica" (1991, p. 3). Para a autora, tudo o que as pessoas dizem umas às outras são textos, que seriam então uma "ocorrência lingüística, de qualquer extensão, dotada de unidade sociocomunicativa semântica e formal" (COSTA VAL, 1991, p.3). Vemos, assim, que os teóricos que desenvolveram percepções sobre texto geralmente apontam as funções sociais e comunicativas como sendo intrínsecas ao seu funcionamento, essenciais ao seu uso. O conceito de texto abre espaço, então, para que a textualidade seja definida como o "conjunto de características que fazem com que um texto seja um texto, e não apenas uma seqüência de frases". (COSTA VAL, 1991, p.5).

${ }^{16}$ No original: "can engender originality, when the connections stem from the being of the creator". 
Os conhecimentos prévios da estrutura e funcionamento do texto, sejam eles os semânticos/formais (coerência e coesão) ou os pragmáticos (intencionalidade, aceitabilidade, situacionalidade, informatividade e intertextualidade) são os mecanismos centrais da textualidade, eles atuam no cerne desse material e garante que ele seja definido como um texto. 0 mais curioso é que esses mecanismos nem sempre se dão de forma consciente, deliberada, como é o caso do critério que nós adotamos como principal, o da intertextualidade.

As origens do termo "intertextualidade" remontam às interpretações e avanços inspirados pelas obras do teórico literário russo Mikhail Bakhtin: para Allen, faz sentido citar "Bakhtin como o responsável pela origem, se não do termo 'intertextualidade', mas ao menos de uma visão específica que ajudou outros a articular teorias de intertextualidade" (ALLEN, 2005, p.11).

Bakhtin realizou abordagem diferentemente da de Ferdinand de Saussure com relação ao contexto social no qual as palavras são trocadas. Segundo o estudioso do discurso, quando o sujeito gera uma palavra, ela não é neutra nem livre de avaliação e ambições, nem dissociada da voz dos outros. O sujeito "recebe a palavra da voz de outro e a preenche com aquela outra voz. A palavra entra em seu contexto de outro contexto, permeada com interpretações de outrem. Seu próprio pensamento encontra a palavra já habitada" (BAKHTIN, 1986, p.201).

Em 1980 o termo intertextualidade é criado: na obra Desire in language: a semiotic approach to literature and art, Julia Kristeva afirma que cada palavra, ou texto, é resultado da intersecção de palavras (textos), na qual ao menos uma outra palavra (texto) pode ser lida e que há dois eixos, o horizontal (sujeito-destinatário) e vertical (texto-contexto). Para Kristeva ${ }^{17}$ :

No trabalho de Bakhtin esses dois eixos, que ele chama de diálogo e ambivalência, não são claramente distinguidos. Ainda, o que aparenta ser falta de rigor é de fato um insight primeiramente introduzido na teoria literária

\footnotetext{
17 Tradução nossa. No original: "In Bakhtin's work, these two axes, which he calls dialogue and ambivalence, are not clearly distinguished. Yet, what appears as a lack of rigour is in fact an insight first introduced into literary theory by Bakhtin: any text is constructed as a mosaic of quotations; any text is the absorption and transformation of another. The notion of intertextuality 5 replaces that of intersubjectivity, and poetic language is read as at least double."
} 
por Bakhtin: qualquer texto é construído como um mosaico de citações; qualquer texto é a absorção e transformação de outro. A noção de intertextualidade substituiu aquela da intersubjetividade, e a linguagem poética é lida como pelo menos o dobro (KRISTEVA, 1986, p.37).

Kristeva estabelece o texto como sendo construído a partir de discursos já existentes: os autores realizam uma compilação de materiais já existentes e não criam a partir de suas mentes originais, é uma permutação de textos, no qual as falas se cruzam e se neutralizam. Para a autora, os textos são feitos do "que é por vezes denominado 'o texto cultural (ou social)', todos os diferentes discursos, maneiras de falar e dizer, estruturas e sistemas institucionalmente sancionados que constituem o que chamamos de cultura"18 (KRISTEVA, 1980, p.36), ou seja os textos estão ligados aos processos culturais e sociais correntes. ${ }^{19}$

Beaugrande e Dressler afirmam que a "intertextualidade diz respeito aos fatores que tornam a utilização de um texto dependente do conhecimento de um ou mais textos encontrados" (1981, p. 10). Eles utilizam o exemplo de um motorista que, dirigindo na estrada, avista um sinal dizendo "reduza a velocidade". Para os autores, só é possível a diminuição dessa velocidade se o motorista vinha dirigindo em alta velocidade; a relevância dessa placa de trânsito depende do conhecimento sobre ela e da aplicação da regra sobre determinada situação. O texto da placa de trânsito só faz sentido quando se leva em consideração a intertextualidade presente com o código de trânsito:

\begin{abstract}
A intertextualidade é, de maneira geral, responsável pela evolução dos tipos textuais como classes de textos com padrões típicos de características. Junto a determinado tipo, o recurso da intertextualidade pode ser mais ou menos proeminente. Em tipos como paródias, resumos críticos, refutações ou relatórios, o produtor do texto deve consultar o texto prévio continuamente, e os destinatários do texto vão geralmente necessitar de alguma familiaridade com o primeiro (BEAUGRANDE; DRESSLER, 1981, p.10).
\end{abstract}

\footnotetext{
18 Tradução nossa. No original: "Texts are made up of what is at times styled 'the cultural (or social) text', all the different discourses, ways of speaking and saying, institutionally sanctioned structures and systems which make up what we call culture".

${ }^{19}$ Essa noção de "texto cultural" também é apontada por Allen (2005, p. 35) com a definição de que o texto é uma "prática e uma produtividade" ligadas aos processos culturais e sociais correntes.
} 
O que a revisão de literatura nos oferece é a perspectiva de que os textos são compostos por diferentes falas, as quais são rearranjadas, reproduzidas e capazes de trazer à tona algo aparentemente "novo", mas cuja novidade reside no quanto o autor soube avançar em seu domínio simbólico, o quanto ele soube trabalhar a intertextualidade em sua obra.

\section{Definição dos critérios de análise}

Realizado em 2012 na Escola Criar e Recrear, voltada para crianças de classe média e classe média alta da capital alagoana, o projeto pedagógico Contos do Como e do Por que é vinculado ao Centro de Educação - Programa de Pós-Graduação em Educação (PPGE/Ufal) e ao Programa de Pós-Graduação em Letras e Linguística (PPGLL/Ufal) Trata-se de um projeto de Língua Portuguesa desenvolvido com alunos do $2^{\circ}$ ano do Ensino Fundamental durante três meses, de abril a junho de 2012. O projeto é de caráter binacional, associado aos estudos do Institut des Textes \& Manuscrits Modernes(ITEM/CNRS) do Laboratório École, Mutations, Apprentissages (EMA, Université de Cergy-Pontoise), dirigido pela Equipe Manuscrit, Linguistique, Cognition (ITEM/CNRS).

Todos os procedimentos de construção do projeto, execução junto às professoras, filmagem das atividades em sala de aula, coleta e digitalização de manuscritos foram realizados pelos alunos participantes do Laboratório do Manuscrito Escolar (L'ÂME/Ufal), que é mantido pelo Grupo de Pesquisa Escritura, Texto \& Criação (ET\&C-CNPq), sob responsabilidade do professor e pesquisador Eduardo Calil.

Com os professores envolvidos, seguindo as orientações gerais do projeto didático, a intenção era promover essa imersão no universo dos contos etiológicos ${ }^{20}$, ou contos de origem, no sentido de construir a sustentação para que os alunos pudessem produzir seus próprios textos. Segundo o projeto, esse tipo de narrativa ainda é pouco conhecido e mencionado nos livros didáticos e materiais

\footnotetext{
${ }^{20}$ Foram escolhidos 35 contos etiológicos para serem lidos nos meses de realização do projeto.
} 
complementares oferecidos aos professores do Ensino Fundamental e ressalta-se a importância da presença de contos de diversas origens, como africana e indígena, "além daqueles que explicam diferentes aspectos e fenômenos da natureza" (CALIL, 2012, p.8).

O objetivo do projeto de escrita era o trabalho com contos ${ }^{21}$ chamados de "conto de origem, conto etiológico, conto do 'como' e do 'por que', contos das origens". Para Câmara Cascudo (2006, p.34), essas narrativas buscam explicar um "aspecto, propriedade, característica de qualquer ente natural. Assim, há contos para explicar o pescoço longo da girafa, a inimizade entre o gato e o rato, a carapaça do jabuti". Os consagrados autores Rudyard Kipling e Ovídio são citados no projeto como sendo autores de contos etiológicos.

Os manuscritos produzidos no projeto didático Contos do Como e do Por Que foram todos digitalizados e catalogados de acordo com o nome dos integrantes e a data em que o texto foi produzido. Segue a descrição na tabela abaixo:

Tabela1. Detalhamento do corpus do projeto Contos do Como e do Por que

\begin{tabular}{|c|c|c|c|c|c|}
\hline \multicolumn{6}{|c|}{ PROJETO CONTOS DO COMO E DO POR QUE } \\
\hline Ano & Turno & \multicolumn{3}{|c|}{ Número parcial de manuscritos } & No total de \\
\hline \multirow{4}{*}{2012} & \multirow{2}{*}{ Matutino } & Individual & Duplas & Trios & \multirow{2}{*}{65} \\
\hline & & 21 & 37 & 7 & \\
\hline & \multirow[t]{2}{*}{ Vespertino } & Individual & Duplas & Trios & \multirow[t]{2}{*}{78} \\
\hline & & 67 & 11 & 0 & \\
\hline & \multirow{2}{*}{$\begin{array}{l}\text { Total } \\
\text { (Matutino } \\
+ \\
\text { Vesnertino) }\end{array}$} & Individual & Duplas & Trios & \multirow[t]{2}{*}{143} \\
\hline & & 88 & 48 & 7 & \\
\hline
\end{tabular}

Fonte: Projeto Contos do como e do Por que (2012)

21 As principais características do conto etiológico são: títulos geralmente acompanhados de interrogações; o tempo da narrativa é geralmente remoto, não especificado e marcado por algumas expressões como "há muito tempo atrás" e "é por isso que hoje", que são responsáveis por situar a narrativa em antes e depois; a narrativa não se articula por meio das personagens, podendo haver a antropomorfização dos animais, diferindo dos contos de fada, nos quais as personagens principais são geralmente príncipes e reis (CALIL, 2012, p.4). 
O corpus levantado no desenvolvimento da pesquisa foi composto de 143 manuscritos, sendo 88 textos individuais, 48 textos em duplas e 7 em trios. Todos os textos foram coletados como resultado do projeto 'Contos do Como e do Porque'. Durante a pesquisa, foram analisados, de forma mais detalhada, 20 textos, 12 individuais e 8 em dupla, considerados os mais criativos a partir dos critérios delimitados.

Buscamos uma intersecção entre diferentes áreas de estudo no campo da produção textual e da análise de textos. Para solidificar a construção da análise nos aspectos relativos a intertextualidade, utilizamos os estudos de Linguística Textual de Bazerman (2007; 2011), Koch (2008), Koch \& Elias (2010) e Marcuschi (2008).

Por se tratarem de manuscritos, abordamos os estudos da Genética Textual de Gresillón (2007) e da Psicolinguística de Calil (2004; 2007; 2009; 2012). Além disso, ancoramos essa construção metodológica nos estudos textuais de Antunes (2010) e nos de Maksić e Ševkušić (2012) para as reflexões sobre os aspectos da criatividade.

Definimos, assim, quatro macrocritérios de análise, subdivididos em 19 subcritérios (apresentados no quadro do próximo item). Os tópicos são os seguintes: 1-Intertextualidade ampla

2-Intertextualidade pela padronização da linguagem social em uso 3-Brincadeira com a linguagem

4-Originalidade de ideias, autenticidade, imaginatividade.

Com tais critérios desenhados, procedeu-se à análise dos manuscritos, aplicando os critérios específicos, com o intuito de provar que os textos que abrangem mais tópicos de intertextualidade, brincadeira com a linguagem e originalidade são os mais criativos. No próximo tópico iremos oferecer alguns números obtidos a partir da análise.

\section{Manuscritos escolares: intertextualidade, brincadeira com a linguagem e originalidade de ideias}


Tendo os critérios específicos definidos, uma análise prévia permitiu a préseleção de 20 textos para uma análise mais minuciosa -8 de alunos do turno matutino e 12 de alunos do turno vespertino. Foram 12 textos individuais (Matutino=2, Vespertino $=10$ ) e 8 textos de duplas (Matutino $=6$, Vespertino $=2$ ). Em nossa análise esses foram os textos com o maior número de tópicos delineados em nossa análise específica, que atingiram os quatro tópicos principais (e a subdivisão em microcritérios). Para efeito de comparação consideramos as variáveis individual/dupla e masculino/feminino

Os textos individuais mantiveram médias de ocorrência semelhantes às dos textos em dupla. A média geral de ocorrência dos critérios foi de 7,08 critérios $(37,26 \%)$. O único texto masculino individual garantiu a média de 7 ocorrências $(36,8 \%)$ e os textos femininos mantiveram a média de 7,09 ocorrências (37,3\%).

Não tivemos substanciais diferenças de número de ocorrência nos textos em dupla em relação aos individuais. Apenas nos chamou a atenção a diferença de ocorrência dos critérios nos textos femininos em dupla, 29,4\%, dos femininos individuais, 37,3\%. A partir dessa diferença podemos pensar que o trabalho realizado individualmente pelas garotas avançou mais no domínio simbólico, embora não possamos conjecturar as razões específicas para tais diferenças.

Demonstramos também a percentagem de ocorrência dos critérios nos textos, para assim estabelecer quais foram os principais pontos que nos fizerem escolher aquele determinado texto como sendo mais criativo. A tabela a seguir indica qual foi a ocorrência dos tópicos nos textos individuais, em dupla, e no contexto geral.

QUADRO 1: Ocorrência dos critérios de análise de intertextualidade e criatividade

\begin{tabular}{|c|c|c|c|}
\hline \multirow{2}{*}{ TÓPICOS } & \multirow{2}{*}{ CRITÉRIOS DE ANÁLISE } & \multicolumn{2}{|c|}{ OCORRÊNCIA } \\
\hline & & INDIVIDUAIS & DUPLAS \\
\hline \multicolumn{4}{|c|}{ INTERTEXTUALIDADE } \\
\hline \multirow{4}{*}{$\begin{array}{l}\text { INTERTEXTUALIDADE } \\
\text { AMPLA }\end{array}$} & Discurso anônimo do senso comum & 6 & 5 \\
\hline & Relações intertextuais não intencionais & 1 & 3 \\
\hline & Intertextualidade temática & 8 & 6 \\
\hline & Intertextualidade implícita: memória coleti & 6 & 2 \\
\hline \multirow{3}{*}{$\begin{array}{l}\text { INTERTEXTUALIDADE } \\
\text { PELA PADRONIZAÇÃO } \\
\text { DA LINGUAGEM }\end{array}$} & Intertextualidade tipológica & 0 & 2 \\
\hline & Interdisciplinaridade & 5 & 4 \\
\hline & Bens de consumo significados no momentc & 4 & 6 \\
\hline
\end{tabular}


De Novo Creari:

Análise de manuscritos escolares por meio de tópicos de intertextualidade e criatividade

\begin{tabular}{|c|c|c|c|}
\hline \multirow[t]{4}{*}{ SOCIAL EM USO } & histórico-cultural & & \\
\hline & Modelo cognitivo de contexto & 3 & 7 \\
\hline & Estrutura de gêneros: retomada de modelc & 0 & 9 \\
\hline & $\begin{array}{l}\text { Título como sinalização do universo em qu } \\
\text { seleção de sentidos deve ser empreendida }\end{array}$ & 5 & 6 \\
\hline \multicolumn{4}{|c|}{ CRIATIVIDADE } \\
\hline \multirow[t]{4}{*}{$\begin{array}{l}\text { BRINCADEIRA COM } \\
\text { A LINGUAGEM }\end{array}$} & $\begin{array}{l}\text { Desprezo deliberado por regras gerais } \\
\text { de linguagem }\end{array}$ & 0 & 0 \\
\hline & $\begin{array}{l}\text { Poder mágico das palavras: brincando com } \\
\text { cores, palavras, sons }\end{array}$ & 0 & 3 \\
\hline & $\begin{array}{l}\text { Uso de figuras de linguagem } \\
\text { (metáforas, ironia, gradação, símbolos) }\end{array}$ & 2 & 5 \\
\hline & Harmonia e beleza da expressão & 2 & 2 \\
\hline \multirow{5}{*}{$\begin{array}{l}\text { ORIGINALIDADE DE IDEIAS, } \\
\text { AUTENTICIDADE, } \\
\text { IMAGINATIVIDADE }\end{array}$} & Encontrando linguagem própria & 4 & 3 \\
\hline & Desistência do pensamento lógico e raciona & 1 & 5 \\
\hline & $\begin{array}{|llll|}\begin{array}{l}\text { Imaginação, habilidade de "unir" } \\
\text { distantes }\end{array} & \\
\end{array}$ & 3 & 9 \\
\hline & Criar novas condições e lugares & 1 & 1 \\
\hline & Visão multi-perspectiva do mundo & 0 & 2 \\
\hline
\end{tabular}

Podemos dividir então os critérios de ocorrência por categorias mais amplas, como demonstrado no gráfico a seguir, com a média de ocorrência dos tópicos no amontoado geral de manuscritos. A soma total do alcance dos critérios, resultado da soma de alcance de cada critério dividido pelo número deles, foi igual a 27,05.

Gráfico 1: Média de alcance dos critérios estabelecidos.

\section{Média de alcance dos critérios estabelecidos}

\footnotetext{
- Intertextualidade Ampla

- Intertextualidade pela padronização da linguagem social em uso

Brincadeira com a linguagem

- Originalidade de ideias, autenticidade, imaginatividade
}

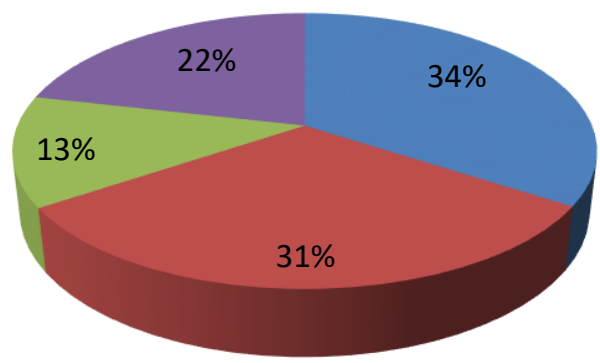

Entretextos, Londrina, v. 17, n. 2, p. 77 - 103, jul./ dez. 2017 
As ocorrências da Intertextualidade ampla foram muito presentes nos textos encontrados, tendo destaque a intertextualidade temática, presente em 14 dos 20 textos analisados, ou seja, em $70 \%$ dos textos nós podemos observar a intertextualidade temática sendo aplicada aos manuscritos. A média de ocorrência de tópicos de intertextualidade ampla é de 7,75 ocorrências.

A Intertextualidade pela padronização da linguagem social em uso também esteve muito forte nos escritos analisados, principalmente o 'Título como sinalização do universo em que a seleção de sentidos deve ser empreendida', com 11 ocorrências. A média geral desse tópico foi de 8,5 ocorrências em 20 textos, 42,5\% do total.

O tópico Brincadeira com a linguagem não foi exatamente forte nos textos analisados. Muito se pode depreender do fato de que os alunos estão ainda recémsaídos da alfabetização, construindo sua maneira de escrever e alguns dos processos descritos na brincadeira com a linguagem vão requerer mais leituras e mais aprofundamento nos fatores sociais e culturais do desenvolvimento dessas crianças. A média de ocorrência dos critérios de brincadeira com a linguagem foi de apenas 3,5 ocorrências, $16,75 \%$.

Finalmente, o tópico Originalidade de ideias, autenticidade, imaginatividade já foi um pouco encontrado do que o anterior, elevado, principalmente, pela ocorrência em 12 textos, do tópico 'Imaginação, habilidade de unir objetos distantes'. A média de ocorrência do tópico foi de 5,8 ocorrências, ou $29 \%$.

Como maneira de apresentarmos uma síntese, a partir dos números apontados anteriormente, no próximo item demonstraremos, a partir de uma amostra de dois textos, escolhidos dentre os vinte que foram estatisticamente tratados nos parágrafos anteriores, a maneira pela qual textualizamos nossa análise. Para isso foram escolhidos os manuscritos: Como surgiram as palavras, de autoria de C e I, uma dupla de meninos, e O Fogo do Vulcão, de A e M. ${ }^{22}$. Os textos foram produzidos no mesmo dia,

\footnotetext{
${ }^{22}$ Por motivos éticos optamos por não divulgar o nome das crianças, preservando assim sua identidade. A identificação será feita apenas por suas iniciais.
} 
durante a aula de português, a consigna oferecida pela professora foi a de que as duplas deveriam inventar uma história que narrasse como surgiu algo/alguma coisa.

\subsection{Análise do texto Como surgiram as palavras}

A seguir, a transcrição de um dos textos analisados produzidos pelos alunos $C$ e I ${ }^{23}:$

Texto 1: Como Surgiram as Palavras, de $C$ e I COMO SURGIRAM AS PALAVRAS

1.A MUITO TEMPO ATRÁS NÃO ESISTAM AS PALAVRAS

2. E AS PESSOAS SE COMUNICAVAM ATRAVÉS DE

3. TELEFONES. UM HOMEM QUERIA

4. ESCREVER AS PALAVRAS, MAS ELAS NÃO EXISTIAM

5. E OUVIU DIZER QUE TINHA UM MAGO NA MONTANHA

6. MAIS ALTA QUE PODERIA AJUDÁLO. PARA ELE CHEGAR

7. NA MONTANHA TERIA QUE PASSAR POR FLORESTAS E

8. RIOS. NA FLORESTA ELE ENCONTROU TIGRES, COBRAS,

9. ARANHAS, MORCEGOS E ESCORPIÕES MAS CONSEGUIU PASSAR.

10. NO RIO ELE ENCONTROU COBRAS D'ÁGUA 11. CROCODILOS, PIRANHAS E OUTROS ANIMAIS AQUÁTICOS, MAS PASSOU POR TUDO E CHEGOU NO

12. TOPO DA MONTANHA E PEDIU AO MAGO QUE ELE 13. CRIASSE AS PALAVRAS E FIM.

Os textos escritos pelos alunos no dia 11 de junho de 2012, apesar do título dado pela professora ser único para todos, demonstram, de maneiras variadas, como a intertextualidade pode ser demonstrada como índice criativo, a exemplo do texto de C e I, demonstrativo dos tópicos que podemos observar.

A orientação temática é muito bem conduzida. O tema do surgimento das palavras nos leva a ponderar que os alunos consideraram a diferença entre a palavra falada e a palavra escrita. Na história inventada, há muito tempo as palavras não existiam e as pessoas se comunicavam por telefones. Esse momento parece nos oferecer a alusão de 'que palavras só podem ser consideradas palavras' quando

\footnotetext{
${ }^{23}$ A transcrição que realizamos aqui, a partir do manuscrito, chama-se 'transcrição diplomática', ou seja, ela mantém as supostas 'incorreções' existentes no manuscrito, buscando representar de maneira mais fiel o que está escrito no manuscrito.
} 
escritas. A comunicação só podia ser feita por meio da palavra falada, por meio desse bem de consumo chamado telefone.

Um homem, então, queria escrever as palavras, que até aquele momento não existiam, por isso ele "ouviu dizer" que um mago que habitava as montanhas poderia ajudá-lo. Nessa etapa da trama, os alunos iniciam um processo de aparente interdisciplinaridade, que faz parte do tópico 'Intertextualidade pela padronização da linguagem social em uso'. O conteúdo das aulas de ciências invade a história inventada: para chegar até esse mago é necessário que o homem, protagonista da história atravesse florestas e rios:

Figura 1. Intertextualidade intergênero no manuscrito: Como surgiram as palavras

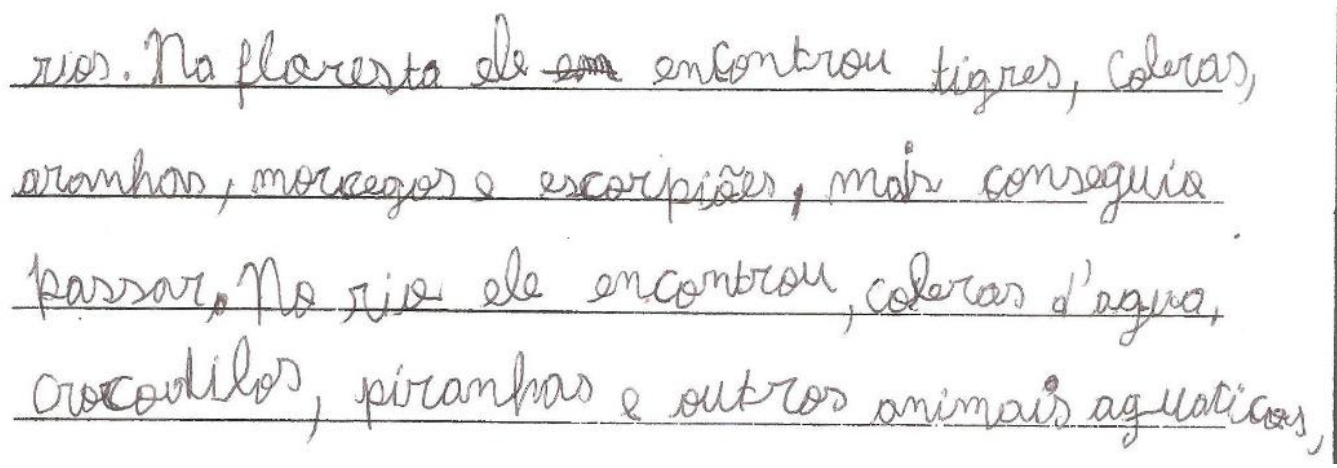

No trecho apontado acima, fica evidente a utilização da intertextualidade em um diálogo realizado entre a história inventada e os temas das outras disciplinas além da Língua Portuguesa. Os dois ambientes naturais, e os animais que ali se encontram, são inseridos na história como obstáculos para que o protagonista chegue até o mago. A intertextualidade implícita, da memória coletiva, que faz parte do tópico ${ }^{24}$ 'Intertextualidade Ampla' é observada, memória que entende a trajetória do herói das histórias fantásticas como sendo geralmente complicada, cheia de percalços. Após passar por tudo isso, subitamente a história termina. O mago cria as palavras e a história tem seu fim.

\subsection{Análise do texto 'O fogo do vulcão'}

\footnotetext{
${ }^{24}$ Para Koch, Bentes e Cavalcante (2008, p.30) "têm-se a intertextualidade implícita quando se introduz, num texto, intertexto alheio sem qualquer menção explícita da fonte".
} 
Partimos agora para um texto, com tema livre, escrito por uma díade de garotas, A e M, ao qual elas deram o título 'O fogo do vulcão':

Texto 2: 'O fogo do vulcão', de A e M.:

1. A MUITO TEMPO ATRÁS EXISTIAM 2

2. FADAS CHAMADAS BLOOL E FLORA, NESSE

3. TEMPO A FLORA FEZ UMA PORÇÃO PARA

4. O VULCÃO CRIAR VÁRIOS TIPOS DE FLORES

5. (EM VEZ DE FOGO) MAS BLOOL ACHOU ERRADO MAS FLORA QUERIA O VULCÃO

6. BONITO ENTÃO ELAS DISCUTIRAM E CHE-

7. GARAM A UM ACORDO, SEM QUERER

8. ELAS JUNTAM OS PODERES ENTÃO

9. CRIOU ÁGUA, ENTÃO ELAS NÃO SABIAM

10. O QUE FAZER, FORAM ATÉ A GELADEI-

11. RA E QUERIAM COCA-COLA MAS A

12. COCA ESTAVA CONGELADA, ENTÃO LEM-

13. BRARAM DO FOGO A BLOOL IA

14. FAZER A MAGIA SÓ QUE A MAGIA

15. NÃO ESTAVA CARREGADA, PEGARAM O MAPA NA GELADEIRA E FORAM EM

16. BUSCA DO MAGO DE PERNAMBUCO

17. E O MAGO PEGOU A PORÇÃO JOGOU

18. NA BLOOL, FORAM DIRETO PARA O VUL-

19. CÃO E BLOOL FEZ O FOGO E ATÉ HOJE O VULCÃO TEM FOGO

20. FIM

Em $O$ fogo do vulcão, A e M utilizam duas personagens já existentes em outro contexto, as fadas Bloom e Flora, estrelas de um jogo on-line. As alunas escrevem o nome de Bloom com a grafia Blool, mas nos parece plausível que tiraram o nome das fadas desse joguinho on-line ${ }^{25}$. Esse tipo de jogo, em Flash, que não requer a instalação do software no computador, é muito comum no universo infantil. No jogo Bloom vs. Flora, o desafio é vestir as fadas com algumas peças de roupas disponíveis. É uma competição fashion entre elas. As alunas terem utilizado o nome das fadas em sua história é um claro indício de intertextualidade temática, que faz parte do tópico 'Intertextualidade Ampla': tratam-se de personagens de um jogo, um suporte on-line no qual personagens são desenvolvidas, entrando em uma história ficcional.

\footnotetext{
${ }^{25}$ Descrição do jogo: "Bloom e Flora querem mostrar que mesmo sendo fadas entendem de moda tanto quanto nós e você terá de criar um look para as duas, combinando cada peça de roupa e não se esquecendo das asas delas". Disponível em: <http://clickjogos.uol.com.br/jogos/winx-club-fashionbloom-vs-flora/>.
} 
O texto de A e M compõe uma história inusitada, na qual as fadas entram em um dilema estético: Flora fez uma poção para que o vulcão tivesse vários tipos de flores, em vez de fogo. Blool não concordou, o que gerou uma discussão entre as fadas, que, ao unir os poderes, fogo+flores, criaram a água. Ao criarem a água, elas não sabiam o que fazer. Nesse momento, sem saber como agir, vão até a geladeira tomar uma Coca-Cola. Porém, a Coca-Cola estava congelada e necessitaria do fogo para descongelar. Só que agora o fogo não existia mais, ou, como as alunas escrevem, "a magia não estava mais carregada". As fadas, então, pegam um mapa na geladeira e vão em busca da ajuda do Mago de Pernambuco, que joga o fogo em Blool - fogo esse que vai direto para o vulcão e se mantém até hoje.

Há muitos pontos a serem analisados nesse manuscrito. No que concerne aos tópicos da criatividade, encontramos harmonia e beleza de expressão ("foram em busca do Mago de Pernambuco"), a desistência do pensamento lógico e racional (um vulcão que tem flores em vez de fogo), a imaginação, a habilidade de unir objetos distantes (fadas, flores, Coca-Cola, mapas, vulcão, mago) e uma visão multiperspectiva do mundo, todos critérios que fazem parte dos tópicos 'Brincadeira com a Linguagem' e 'Originalidade de Ideias, Autenticidade e Imaginatividade'.

As alunas seguem, também, o modelo cognitivo de contexto e utilizam demais os bens de consumo significados no momento histórico-cultural, parte do tópico 'Intertextualidade pela padronização da linguagem social em uso'. A Coca-Cola entra na história como algo corriqueiro, que se faz enquanto se pensa sobre determinado problema; há o mapa grudado na geladeira, que leva as fadas até Pernambuco. Outro fato que chama a atenção é a afirmação das alunas de que "a magia não estava carregada", em uma linguagem típica de jogos (nos quais os poderes têm que estar carregados - "loaded" - para serem acionados). As autoras fazem uma interessante intertextualidade temática: presença do Mago, comum em boa parte dos manuscritos escritos em duplas, atesta o desfecho clássico de alguns textos etiológicos, nos quais existe sempre uma personagem superior, que oferece um desfecho para a trama.

\section{Considerações Finais}


O estudo nos permitiu a observação de que nos manuscritos selecionados e analisados, os critérios de intertextualidade (Ampla e Pela Padronização da Linguagem Social em Uso) se impuseram àqueles que colocamos como sendo critérios estritamente relacionados à criatividade (Brincadeira com a Linguagem e Originalidade de Ideias, Autenticidade e Imaginatividade) . A proporção foi de $65 \%$ de intertextualidade para $35 \%$ de criatividade. Isso nos garante ter segurança para afirmar que, na criação de textos etiológicos por crianças recém-saídas da alfabetização, a intertextualidade é um dos pontos de maior relevância.

Em 'Como surgiram as palavras' os autores mesclam fantasia a elementos da rotina. Estudando sobre os ambientes naturais eles inscrevem animais aquáticos e terrestres, obstáculos ao progresso do protagonista da história. Esse conhecimento se dá forma de listas, são vários animais que surgem da memória desses escreventes e se manifestam naquele texto. Fica claro para nós que a exposição a diferentes textos em sala de aula ajudou a consolidar a estruturação de uma narrativa história inventada, com início, obstáculos e desfecho.

'O Fogo do Vulcão' resulta de um interessante jogo de imaginação por uma díade de garotas, que dá outro significado às personagens de um jogo de videogame e traz elementos do dia a dia ao modelo cognitivo de contexto. $O$ aspecto criativo presente no desfecho que elaboram é evidenciado por uma série de eventos inusitados que permitem à dupla de fadas descobrirem um mapa, grudado em uma geladeira, o caminho para Pernambuco, e, assim, para o Mago de Pernambuco e trazer de volta o fogo para o vulcão.

Os resultados nos ajudam a entender a criatividade a partir do momento em que o aluno insere os bens de consumo como elementos integrantes de um conto etiológico, quando ele realiza relações intertextuais não intencionais, ou seja, por serem ainda escreventes em desenvolvimento nos parece pouco provável que eles possam criar possibilidade de localização das referências que usam em seus textos, que remetam, intencionalmente a outros contextos. O movimento que eles realizam traz personagens e fatos de outros universos para os contos, quando trabalha temas de outras disciplinas/suportes culturais. 
Em nossa opinião, balizada nas análises que empreendemos, um texto criativo viaja por diferentes espaços e pode, ainda assim, sofrer a influência do discurso do senso comum e de seus conceitos e preconceitos socialmente estabelecidos. Um texto criativo retoma esses modelos e os desconstrói, os remodela, dá nova face, gosto, cheiro para aquele modelo. Também pudemos sentir a criatividade nos textos já pelos títulos: neles, já sentimos um pouco do que está por vir, ou do potencial do aluno para o avanço naquele domínio simbólico.

Quando analisamos a criação de histórias inventadas por alunos recémalfabetizados, em contexto escolar, podemos concluir que a criatividade é gerar lugares novos, mundos novos, personagens novas, sem deixar de dialogar com os clássicos, com o legado cultural dos que sentiram que o papel no mundo era o de ser um criador. As possibilidades as quais esses estudantes foram expostos, com uma dedicação das professoras ao projeto e uma verdadeira imersão no universo dos contos etiológicos permitiu que eles também pudessem brincar com a linguagem, sem, no entanto, escapar de um formato narrativo, de uma estrutura estabelecida. Além disso os alunos e alunas participantes demonstraram a capacidade de criar algo autêntico, misturando referências de outros contextos de letramento.

\section{Referências}

ALBUQUERQUE, Maria de Fátima Mamede de. A produção do texto criativo no contexto de sala de aula: o caso dos alunos de 12/13 anos. 1992. 645f. Tese (Doutorado em Didática do Português), Departamento de Didática e Tecnologia Educativa, Universidade de Aveiro, Aveiro, Portugal, 1992.

ALLEN, Graham. Intertextuality. Londres: Routledge, 2011.

ANTUNES, Irandé. Análise de textos: fundamentos e práticas. São Paulo: Parábola Editorial, 2010

BAKHTIN, Mikhail. Estética da criação verbal. São Paulo: Martins Fontes, 1992.

. Problems of Dostoyevski's poetics. C. Emerson (tradução e edição). University of Minnesota Press, Minneapolis, MN, 1984.

BAZERMAN, Charles. Escrita, gênero e interação social. São Paulo: Contexto, 2007. 
BAZERMAN, Charles. Gênero, agência e escrita. São Paulo: Cortez, 2011.

BEAUGRANDE, Roberl-Alain de; DRESSLER, Wolfgang. Introduction to Text Linguistics. Londres: Longman, 1981.

CALIL, Eduardo (Org.). Contos do Como e do Por que: Projeto Didático 2012. Maceió: Programa de Pós Graduação em Educação/Universidade Federal de Alagoas, 2012.

.A menina dos títulos: repetição e paralelismo em manuscritos de Isabel.São Paulo: Alfa; v. 54, n.2, p. 533-564, 2010.

. A Rainha Comilona: dialogismo e memória na escritura escolar. São Paulo: Bakhtiniana, v.7, p. 24-45, jan/jun. 2012.

. Autoria: a criança e a escrita de histórias inventadas. 2.ed. Londrina: Eduel, 2009a.

. Um manuscrito escolar e a interferência da homonímia no processo de escritura. Revista do Gelne. João Pessoa, v. 6, n. 2, p. 61-72, 2004.

. Escutar o invisível: escritura \& poesia na sala de aula. São Paulo: Editora Unesp; Rio de Janeiro: Funarte, 2008.

CALIL, Eduardo; LIMA, Maria Hozanete Alves de. Nomes próprios em histórias inventadas: odores de um encadeamento. In: Eduardo Calil (Org.). Trilhas da escrita: autoria, leitura e ensino. São Paulo: Cortez, 2007. p. 111-131.

CALIL, Eduardo; DEL RE, Alessandra. Análise multimodal de uma história inventada: o caso da onomatopeia visual .Multimodalidade e Intermidialidade: abordagens lingüísticas e literárias. Revista da Anpoll. Florianópolis, v. 2, n.27, p.13-41, 2009.

CASCUDO, L. C. Contos Tradicionais do Brasil. São Paulo: Global, 2006.

COSTA VAL, Maria das Graças. Redação e textualidade. São Paulo: Martins Fontes, 1991.

CSIKSZENTMIHALYI, Mihaly. Creativity: flow and the psychology of discovery and invention. EUA: Harper Perennial, 1996.

GRESILLON, Almuth. Elementos de crítica genética: ler os manuscritos modernos. Porto Alegre: Editora da UFRGS, 2007.

KOCH, Ingedore. Intertextualidade: diálogos possíveis. São Paulo: Cortez, 2008. 
$\mathrm{KOCH}$, Ingedore Villaça; ELIAS, Vanda Maria. Ler e escrever: estratégias de produção textual.São Paulo: Contexto, 2010.

KOLP, Pierre. LA CREATIVITÉ considérée d'un point de vue historique et considérée d'un point de vue actuel. Centre de Formation de I"enseignement de I"UVCB, 19 de março de 2009, à Braine-l“'Alleud, Bélgica, 2009.

Kristeva, Julia. Word, Dialogue and Novel. In: MOI, Toril (org.). The Kristeva Reader. New York: Columbia University Press, 1986, p. 34-62.

KRISTEVA, Julia. Desire in language: a semiotic approach to literature and art. Thomas Gora, Alice Jardine e Leon S. Roudiez (trad.). New York: Columbia University Press, 1980.

LUBART, T. Creativity, high potential and assessment issues. In: THE $11 \mathrm{TH}_{\mathrm{H}} \mathrm{ECHA}$ CONFERENCE: FROM GIFTEDNESS TO SUCCESSFUL INTELIGENCE, Praga, 16-20 de setembro, 2008,

MAKSIĆ, Slavica; ŠEVKUŠIĆ, Slavica. Creativity of Students' stories: case study at primary school. Proceedings of the Institute for Educational Research, Belgrado, v. 44, n. 1, p. 128-143, 2012.

MARCUSCHI, Luiz Antônio. Produção textual: análise de gêneros e compreensão.São Paulo: Parábola Editorial, 2008.

MASLOW, A.H. The creative attitude.In: MASLOW, A.H. The farther reaches of human nature. New York: Penguin, 1973. p. 55-68.

RIBOT, T. Essay on the creative imagination. London: Kegan, Paul, Trench, Trübner \& Co.Ltd., 1906.

ROBINSON, Ken. Libertando o poder criativo: as teorias sobre imaginação, criatividade e inovações que despertam os talentos reprimidos.Trad. Rosemarie Ziegelmaier. São Paulo: HSM Editora, 2012.

ROGERS, Carl. Toward a theory of creativity. In: On becoming a person. Boston: Houghton Mifflin, 1961. p. 347-359.

Sternberg, R.J.. The rainbow project: enhancing the SAT through assessments of analytical, practical and creative skills. Intelligence, v. 34, n.1, p.321-350, 2006.

TATARKIEWICZ, Wladyslaw. A History of Six Ideas an essay in aesthetics. Melbourne: International Volume Series, 1980. 
TORRANCE, E. P. The Torrance Tests of Creative Thinking-Norms-Technical Manual Research Edition-Verbal Tests, Forms $A$ and B-Figural Tests, Forms $A$ and $B$. Princeton. NJ: Personnel Press, 1966. 